\title{
Arrival of excitation at right ventricular apical endocardium in Wolff-Parkinson-White syndrome type A, with and without right bundle-branch block ${ }^{1}$
}

\author{
Cesar A. Castillo, Agustin Castellanos, Jr., B. Befeler, Robert J. Myerburg, \\ Abdul S. Agha, and M. Celeste Vagueiro \\ From the Cardiovascular Laboratory, Veterans Administration Hospital, and the Division of Cardiology, \\ Department of Medicine, University of Miami School of Medicine, Miami, Florida, U.S.A.
}

Filtered bipolar right ventricular apical $(R V A)$ and His bundle electrograms, using electrodes only I mm apart, were recorded in two patients with intermittent WPW type $A$ with and without 'complete' right bundle-branch block. In beats with exclusive normal pathway conduction and 'complete' right bundle-branch block, the $H V$ and $V-R V A$ intervals represented His-to-left ventricular endocardial and left ventricular endocardial-RVA conduction times, respectively. The H-RVA interval was determined by addition of these two intervals. In 'fusion' beats resulting from $A V$ conduction through both normal and accessory pathways, the duration of the H-RVA interval was similar to that of beats with exclusive normal pathway conduction, suggesting that though the ventricles were pre-excited through an accessory pathway the RVA was still activated via the impulse emerging from the right bundle-branch. In beats with exclusive, or predominant, accessory pathway conduction and a WPW type A morphology, the H-RVA 'interval' was 'shorter-thannormal', suggesting that the $R V A$ was not activated by the impulse traversing the normal pathway but by the one propagating from the pre-excited site. The corresponding $V-R V A$ intervals (giving a rough estimate of conduction time from pre-excited site to $R V A$ ) were longer (IIO and 120 msec, respectively) than in two other patients with WPW type B. Intracardiac recordings have enhanced our knowledge of the ventricular activation process in WPW type A, either pure or associated with 'complete' right bundle-branch block.

The diagnosis of right bundle-branch block in patients with Wolff-Parkinson-White syndrome (WPW) has been a subject of considerable debate and speculation (Pick and Fisch, 1958; Robertson et al., 1963; Laham, 1969; Schamroth, 1971). The introduction of specialized techniques for obtaining intracardiac electrograms has offered a new approach to the analysis of ventricular pre-excitation. This will be shown in the present communication which deals with the arrival of excitation at several recording sites in patients having WPW type A associated with persistent, or intermittent, 'complete' right bundle-branch block.

\section{Subjects and methods}

The technique for obtaining His bundle and local venReceived 8 November 1972.

1 This study was supported in part by Institutional Research Funds (Part II) provided by the Veterans Administration Hospital, Miami, Florida, U.S.A. tricular electrograms used in our department has been discussed in other communications (Castellanos, Castillo, and Myerburg, I97I; Castellanos and Castillo, 1972; Castellanos et al., 1972a). After explaining the procedure and obtaining consent from the patient, catheter electrodes were introduced to stimulate the high right atrium and to record from the $\mathrm{His}$ bundle area and the right ventricular apex (RVA). Filtered $(40-400 \mathrm{~Hz})$, bipolar electrograms, using electrodes I mm apart, were obtained simultaneously with leads I, II, III, and VI, at paper speeds of $100 \mathrm{~mm} / \mathrm{sec}$. Data from two patients with WPW type A in whom 'complete' right bundle-branch block also occurred will be presented.

The significance and duration of the various intervals measured are discussed in the corresponding case description.

\section{Case I}

Four types of beats were observed in this 22-year-old man with intermittent WPW type $A$. These respectively resulted from: (a) exclusive normal (AV) pathway con- 


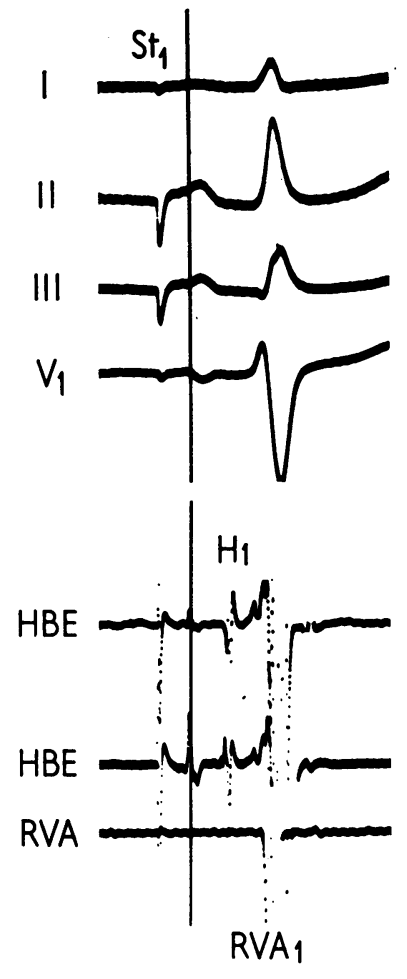

FIG. I Case I. Surface and intracardiac recordings during exclusive conduction through the normal $A V$ pathway. The duration and significance of intervals measured from this beat are shown in Table I. HBE, $H i s(H)$ bundle bipolar electrogram; $R V A$, right ventricular apical bipolar electrogram; St, electric stimulus (delivered to the high right atrium).

In this, and all Figures, paper speed was 100 $\mathrm{mm} / \mathrm{sec}$.

duction without 'complete' right bundle-branch block (Fig. I and Table I); (b), exclusive normal (AV) pathway conduction with functional 'complete' right bundlebranch block (Fig. 2 and Table 2); (c) coexistent normal pathway and accessory pathway conduction ('fusion' complexes, Fig. 3 and Table 3); and (d) exclusive, or predominant, accessory pathway conduction (Durrer $e t$ al., 1967) (Fig. 4 and Table 4).

In Fig. I, the normal AV conduction time and narrow QRS complexes suggested that the impulse reached the ventricles exclusively through the normal pathway. The HV and H-RVA intervals (Table I) had normal values (Castellanos and Castillo, I972; Castellanos et al., I972a, b). Small q waves were not recorded in lead I, aVL, or left chest leads (the latter not shown).

Some of the premature (electrically-induced) atrial impulses were also able to reach the ventricles through the normal pathways, but with functional 'complete'

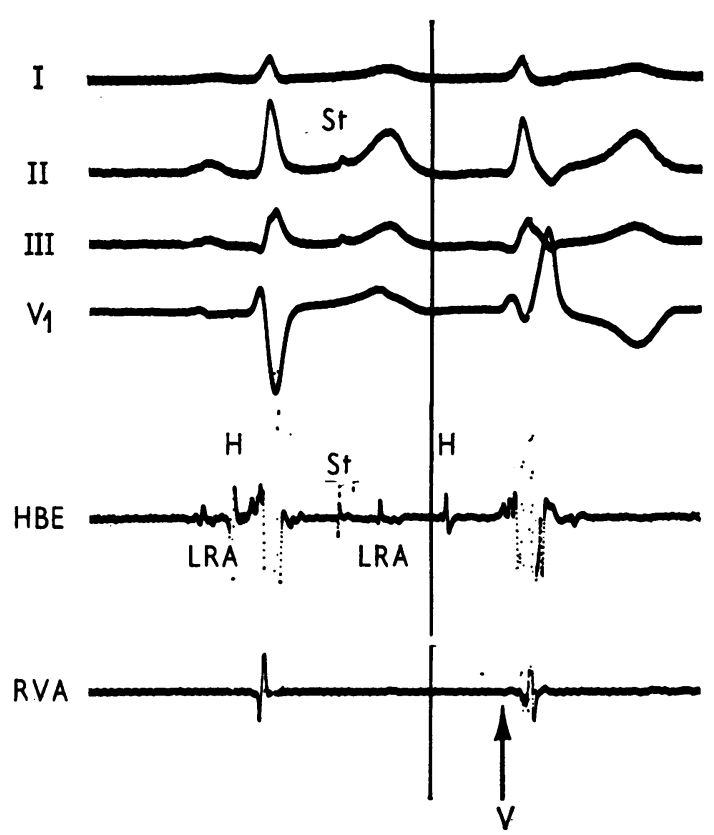

FIG. 2 Case I. Surface and intracardiac recordings during exclusive conduction through the normal $A V$ pathway with functional 'complete' right bundlebranch block. The duration and significance of the intervals measured from the right sided beat are presented in Table 2. LRA, low right atrial electrogram; $V$, onset of ventricular depolarization.

TABLE I Significance and duration of intervals measured in beat resulting from exclusive conduction through normal pathway (Fig. I)

a) StV interval (measured from moment in which stimulus was delivered at high atrium to onset of ventricular depolarization in whichever lead it occurred first)=conduction time through atria, AV node, and His-Purkinje system: $180 \mathrm{msec}$

b) $A H$ interval (measured from low right atrial deflection to His bundle deflection in HBE lead) $=\mathrm{AV}$ node conduction time: $85 \mathrm{msec}$ (normal range: $50-120 \mathrm{msec}$ )

c) $\mathrm{HV}$ interval (measured from $\mathrm{H}$ deflection to beginning of ventricular depolarization in whichever lead it occurred first) $=$ His-Purkinje conduction time: $40 \mathrm{msec}$ (normal range: 55 to $75 \mathrm{msec}$ )

d) $H-R V A$ interval (measured from $\mathrm{H}$ deflection to onset of RVA electrogram) = conduction time from His bundle to RVA through right branch: $60 \mathrm{msec}$ (normal range: 55 to $75 \mathrm{msec})$

e) V-RVA interval (measured from onset of ventricular depolarization in whichever lead it occurred first to RVA electrogram) = interval elapsing between initiation of ventricular depolarization and activation of RVA: $20 \mathrm{msec}$

f) $Q R S$ duration: $95 \mathrm{msec}$ 
TABLE 2 Significance and duration of intervals measured in beat resulting from exclusive $A V$ conduction through normal pathway with functional 'complete' right bundle-branch block (Fig. 2)

a) StV interval $=310 \mathrm{msec}$

c) $H V$ interval = conduction time from His bundle to left ventricular endocardium through left bundle system: 120 msec

d) $V-R V A$ interval = conduction time from left ventricular endocardium to right ventricular endocardium (RVA) through septum: $55 \mathrm{msec}$

e) $H-R V A$ interval $=\mathrm{HV}$ interval (120 msec) + V-RVA interval (55 msec): $175 \mathrm{msec}$

f) $Q R S$ duration $=150 \mathrm{msec}$ b) $A H$ interval $=150 \mathrm{msec}$

TABLE 3 Significance and duration of intervals measured in beat resulting from $A V$ conduction through both normal and accessory pathways (Fig. 3)

a) St $\mathrm{V}$ interval = in beats with any degree of pre-excitation this interval measured conduction time through atria (from the paced site to that where impulse enters accessory pathway) and through accessory pathway itself $=130 \mathrm{msec}$

b) $A H$ interval =even when pre-excitation is present this interval measures AV node conduction time: $125 \mathrm{msec}$

c) $V H$ interval $=\mathrm{H}$ was inscribed after $\mathrm{V}$ because ventricles were pre-excited ahead of His bundle

d) $H-R V A$ interval $=60 \mathrm{msec}$. Since this value was similar to that obtained when exclusive normal pathway conduction was present (Fig. I and Table I) it can be inferred that RVA was still activated by impulse traversing right branch

e) $V-R V A$ interval = interval elapsing between initiation of ventricular depolarization (by impulse traversing the accessory pathway) and activation of RVA (by impulse descending via right branch): $90 \mathrm{msec}$

f) $Q R S$ duration: $170 \mathrm{msec}$

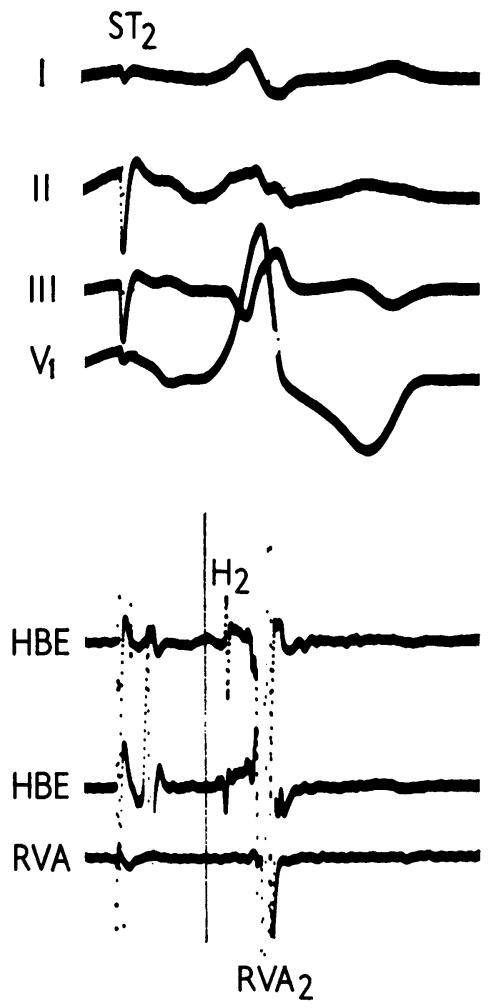

FIG. 3 Case I. Surface and intracardiac recordings in 'fusion' complex resulting from $A V$ conduction through both normal, and accessory, pathways (WPW type $A)$. The duration and significance of pertinent intervals are given in Table 3. Note that the $H$ deflection was inscribed after the onset of ventricular depolarization (thin vertical line). 
TABLE 4 Significance and duration $(\mathrm{msec})$ of intervals measured in beat resulting from exclusive or predominant accessory pathway conduction (Fig. 4)

a) StV interval ${ }^{\star}=130 \mathrm{msec}$

b) $A H$ interval $^{\star}=150 \mathrm{msec}$

c) $V H$ interval $^{\star}=\mathrm{H}$ was inscribed after $\mathrm{V}$ because ventricles were pre-excited ahead of His bundle

d) $H-R V A$ interval = differences between activation time of bundle (by impulse traversing the AV node) and RVA: 45 msec

Since this interval was shorter than normal $(60 \mathrm{msec}$ in Fig. I and Table I), RVA could not have been depolarized by impulse descending through right branch. Hence RVA was most probably activated by impulse propagating from pre-excited area

Therefore:

e) The $V-R V A$ interval of $110 \mathrm{msec}$ represented conduction time from pre-excited area to $R V A$

f) $Q R S$ duration: $185 \mathrm{msec}$

* As defined in Table 3.

right bundle-branch block and prolonged AV conduction time (Fig. 2). The HV interval measured $120 \mathrm{msec}$ (Table 2), suggesting that there was an associated conduction delay through the left bundle system.

Fig. 3 shows a 'fusion' complex (with WPW type A morphology) which occurred when the atrial impulse reached the ventricles through both normal and accessory pathways. This diagnosis was suggested, as shown in Table 3, by: (a) shortening of the StV interval; (b) increase in QRS duration with appearance of a delta wave; (c) inscription of the $\mathrm{H}$ deflection after the onset of ventricular depolarization (Castillo and Castellanos, 1970), and (d) H-RVA interval similar to that in normal beats.

The slightly wider QRS complex shown in Fig. 4 had a similar (short) StV interval. Though the morphology in lead VI resembled that of 'complete' right bundle-branch block, inscription of the $\mathrm{H}$ deflection after the beginning of ventricular depolarization suggested that this beat resulted from exclusive, or predominant, accessory pathway conduction (Durrer et al., 1967). Due to the reasons discussed in Table 4, it was assumed that the RVA was not activated from the right branch but from the pre-excited area.

\section{Case 2}

Fig. 5 and 6 were obtained from a 52-year-old man with intermittent WPW type A who, in 1970, developed 'complete' right bundle-branch block. The first beat in Fig. 5 shows exclusive conduction through the normal pathway with 'complete' right bundle-branch block. The latter diagnosis was based on the characteristic QRS morphology and the (at upper limits of) normal HV interval. The duration of the corresponding intervals is presented in Table 5 .

The second beat in Fig. 5 was a 'fusion' complex resulting from ventricular activation through both normal and accessory pathways. This assumption was
TABLE 5 Significance and duration of intervals in beat (first of Fig. 5) resulting from exclusive $A V$ conduction through normal pathway associated with persistent 'complete' right bundle-branch block

a) StV interval ${ }^{\star}=190 \mathrm{msec}$

b) $A H$ interval ${ }^{\star}=70 \mathrm{msec}$

c) $H V$ interval $\dagger=$ conduction time from $\mathrm{His}$ bundle to left ventricular endocardium (through left bundle system) : 55 $\mathrm{msec}$

d) $V-R V A$ interval $+=$ conduction time from left ventricular endocardium to RVA (across the septum): $55 \mathrm{msec}$

e) $H-R V A$ interval $\dagger=\mathrm{HV}(55 \mathrm{msec})+\mathrm{V}-\mathrm{RVA}(55 \mathrm{msec}): 110$ $\mathrm{msec}$

f) $Q R S$ duration: $160 \mathrm{msec}$

$\star$ As defined in Table $I$.

† As defined in Table 2.
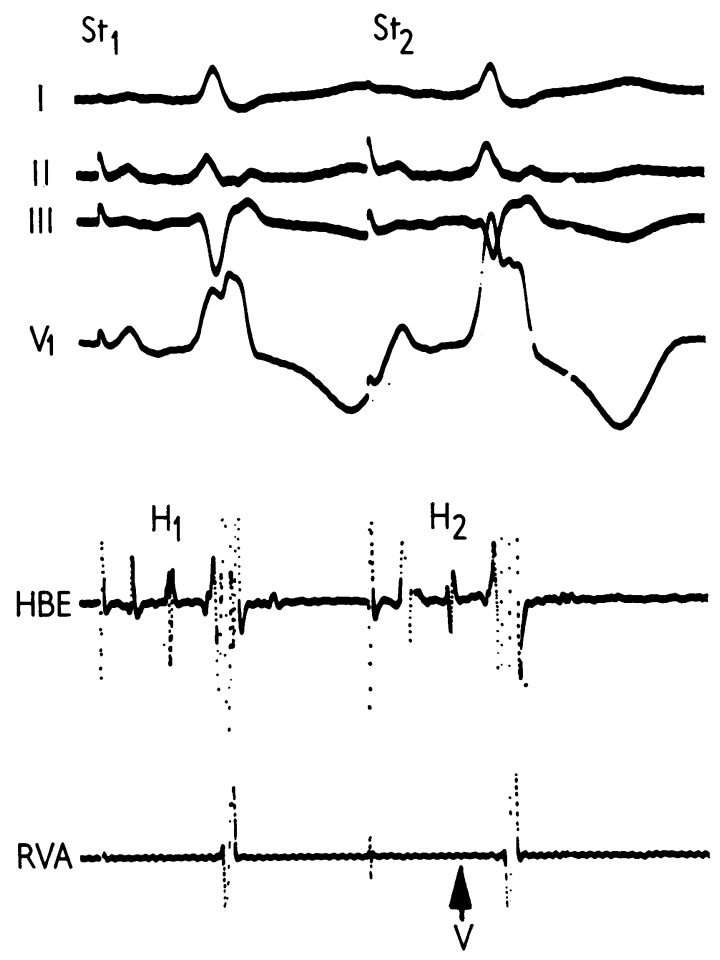

FIG. 5 Case 2. Surface and intracardiac recordings in beats showing exclusive conduction through the normal $A V$ pathway with 'complete' right bundlebranch block (left) and in 'fusion' beats resulting from simultaneous conduction through accessory pathway and normal pathway with 'complete' right bundlebranch block (right). Since this patient had ventricular pre-'excitation' (last beat in Fig. 6) it appears that WPW type A coexisted with 'complete' right bundlebranch block. Duration and significance of most important intervals are presented in Tables 5 and 6. 
TABLE 6 Significance and duration ( $\mathrm{msec}$ ) of intervals measured in beat (last in Fig. 5) resulting from $A V$ conduction through both normal (with complete right bundle-branch block) and accessory pathways

a) StV interval ${ }^{\star}=165 \mathrm{msec}$

b) $A H$ interval ${ }^{\star}=95 \mathrm{msec}$

c) $V H$ interval $^{\star}=\mathrm{H}$ was inscribed with $\mathrm{V}$ because of ventricular pre-excitation ahead of His bundle

d) $H-R V A$ interval = conduction time from His bundle to left ventricular endocardium through left bundle system ( 55 msec in Table 5) and from the left ventricular endocardium to RVA (across septum: $55 \mathrm{msec}$ in Table 5): $110 \mathrm{msec}$

Since this value is similar to that obtained in beats without pre-excitation (Table 5), RVA must have been activated as in these beats

e) $V-R V A$ interval $=$ elapsing between initiation of ventricular depolarization (by impulse traversing accessory pathway) and activation of RVA (following sequence expressed in definition of H-RVA interval): $75 \mathrm{msec}$

f) $Q R S$ duration: $190 \mathrm{msec}$

* As defined in Table 3.

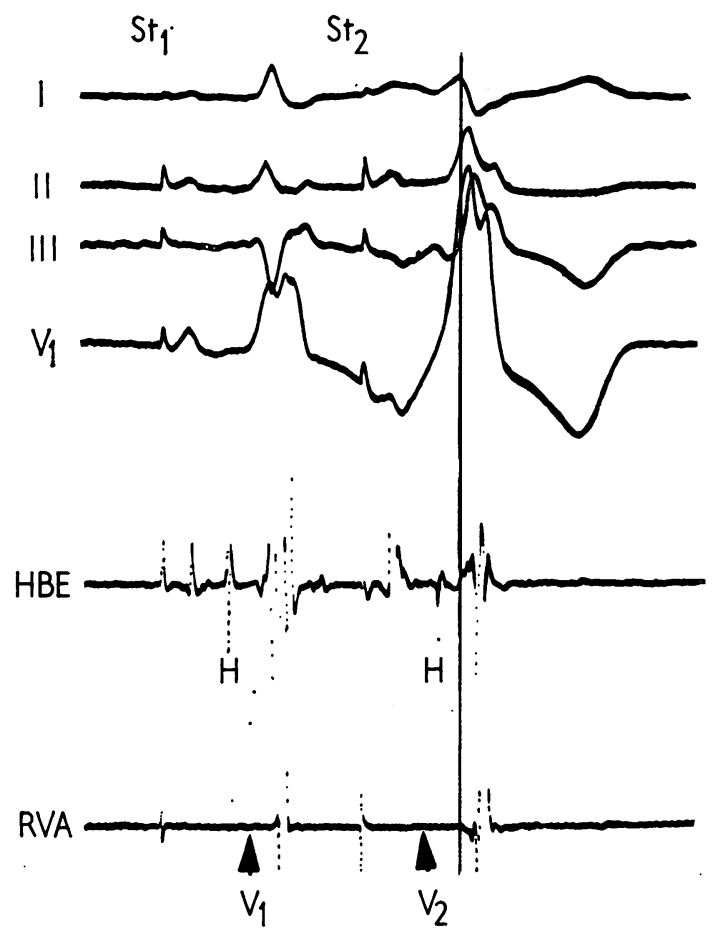

FIG. 6 Case 2. Surface leads and intracardiac electrograms in beats with exclusive $A V$ conduction through the normal pathway with 'complete' right bundle (left) and exclusive or predominant accessory pathway conduction with WPW type $A$ morphology (right). The duration and significance of pertinent intervals are discussed in Table 7.
TABLE 7 Significance and duration of intervals measured in beat (last in Fig. 6) with exclusive or predominant accessory pathway conduction

a) StV interval ${ }^{\star}=130 \mathrm{msec}$

b) $A H$ interval ${ }^{\star}=125 \mathrm{msec}$

c) $V H$ interval $=\mathrm{H}$ was inscribed after $\mathrm{V}$

d) $H-R V A$ interval ${ }^{\star}=$ differences between activation times of His bundle (by impulse traversing AV node) and RVA (by impulse propagating from pre-excited area): $85 \mathrm{msec}$. Since this interval was shorter than in beats without preexcitation (I Io msec in Table 5 ) RVA could not have been depolarized by impulse traversing normal pathway. Hence, RVA was most probably activated by impulse propagating from pre-excited site Hence:

e) V-RVA interval ${ }^{\star}$ of $120 \mathrm{msec}$ represented conduction time from pre-excited area to RVA

f) $Q R S$ duration: $195 \mathrm{msec}$

* As defined in Table 2.

supported by (Table 6): (a) the change in morphology to one between that of 'complete' right bundle-branch block (first beat in Fig. 5) and that of pure WPW type A (last beat in Fig. 6); (b) the shortening of AV conduction time; (c) inscription of the $\mathrm{H}$ deflection at the onset of ventricular depolarization; and (d) the similar duration of the H-RVA interval in this beat and in that with exclusive conduction through the normal pathway with 'complete' right bundle-branch block.

Finally, the last beat in Fig. 6 showed what in this patient appeared to have been exclusive, or predominant, accessory pathway conduction with WPW type A morphology. There was a further shortening of AV conduction time associated with inscription of the $\mathrm{H}$ deflection after the onset of ventricular depolarization (Table 7). The shorter than normal H-RVA interval suggested that the RVA was not depolarized by the impulse traversing the normal pathway but by that propagating from the pre-excited area.

\section{Discussion}

Beat resulting from exclusive normal AV pathway conduction without 'complete' right bundle-branch block (Fig. I and Table I)

In these beats, the H-RVA interval represented conduction time through the His bundle, right branch, and that part of the ordinary myocardium located between the site where the impulse emerged from the right branch and the electrodes positioned at the RVA (Castellanos and Castillo, 1972; Castellanos et al., 1972a, b). On the other hand, the V-RVA interval simply reflected the time elapsing between the beginning of ventricular depolarization (wherever it might have occurred) and activation of the RVA (Castellanos et al., 1972a, b). Since lead I did not show a $q$ wave and left ventricular electrograms were not recorded, it could not be determined 
whether the supraventricular impulse reached the left ventricular endocardium before the right, the latter before the former, or both at more or less the same time.

Beat resulting from exclusive normal AV pathway conduction with functional 'complete' right bundle-branch block (Fig. 2 and Table 2)

In Fig. 2, the presence of (true) 'complete' right bundle-branch block was suggested by the prolonged AV conduction time, the wide QRS complexes, the triphasic pattern in lead $\mathrm{VI}$, the preterminalterminal slurring, and the absence of initial delay. Since the HV interval measured $120 \mathrm{msec}$, an associated conduction delay must have been present within the left bundle-branch. Assuming that the block in the right branch was 'complete', the HV interval most probably represented conduction time from His bundle to left ventricular endocardium (through the left bundle system). Moreover, the V-RVA interval could be used as a rough measurement of conduction time from the left ventricular endocardium to the RVA: left-to-right transseptal conduction time. Therefore, the H-RVA interval gave an estimate of conduction time from His bundle to left ventricular endocardium and from the latter area to the RVA.

Beat resulting from AV conduction through both normal and accessory pathways without 'complete' right bundle-branch block (Fig. 3 and Table 3)

In Fig. 3, pre-excitation of the ventricles through the accessory pathway occurred before that of the $\mathrm{His}$ bundle. Thus, the $\mathrm{H}$ deflection was inscribed after the onset of the delta wave. However, the RVA was activated by the impulse traversing the right branch (from the His bundle) since the duration of the H-RVA interval $(60 \mathrm{msec})$ was similar to that of the beat with exclusive normal pathway conduction and narrow QRS complexes (Fig. I and Table I). Though this beat was a 'fusion' complex, the predominantly positive (wide and monophasic) deflection in lead VI suggested that the impulse arising in the pre-excited area activated most parts of both ventricles. Yet, it reached the RVA after this area had already been depolarized by the activation front emerging from the right bundle-branch.

\section{Beat resulting from exclusive accessory path- way conduction (Fig. 4 and Table 4)}

In contrast to what occurred in Fig. 3 (where a 'fusion' complex was present), Fig. 4 showed that the H-RVA 'interval' was reduced from 60 to 45 msec. This suggests that the RVA was not activated by the impulse emerging from the right branch possibly because the RVA had already been depolarized by the impulse propagating from the preexcited site. Therefore, the V-RVA interval could be used as a rough measurement of conduction time from pre-excited area to RVA.

Beat resulting from exclusive, or predominant, accessory pathway associated with organic 'complete' right bundle-branch block (Fig. 5 and Table 5)

If the block in the right bundle-branch was complete (and persistent), the HV interval gave an indication of His-to-left ventricular endocardium conduction time. In consequence, the V-RVA represented left-to-right transseptal conduction time. The duration of the H-RVA interval was calculated by adding the HV (H-left ventricular endocardial) and the V-RVA (left ventricular endocardial-right ventricular apical endocardial) conduction times (Fig. 2 and 5, Tables 2 and 5).

'Fusion' beat resulting from AV conduction through normal pathway (with persistent 'complete' right bundle-branch block) and through accessory pathway (Fig. 5 and Table 6)

In this beat the impulse propagating from the preexcited site probably did not reach the left ventricular endocardial areas first depolarized by the impulse emerging from the left bundle system in time to render them refractory since the H-RVA interval (determined by the addition of the H-to-left ventricular endocardial and left ventricular endocardial to RVA conduction times) had a similar value (I IO $\mathrm{msec}$ ) to the beat without pre-excitation. A 'fusion' complex was possible because some (anterior) right ventricular regions were not activated from the pre-excited area but by the impulse which, after descending through the left bundle system, propagated in a left-to-right direction across the septum.

Beat resulting from predominant, or exclusive, accessory pathway conduction without 'complete' right bundle-branch block (Fig. 6 and Table 7)

The shorter-than-normal H-RVA interval suggested that the RVA was not activated by the impulse reaching the ventricles through the His bundle. Assuming 'complete' block in the right branch, depolarization of the RVA was most probably a function of the impulse propagating from the preexcited region. Thus, the V-RVA interval of 120 msec represented conduction time from the latter site to the RVA. 


\section{Conduction time from pre-excited area to endocardial surface of RVA}

Although the pathways that the impulse followed in propagating from one site to the other are not known, the morphology of the QRS complexes suggested an anteroposterior and left-to-right sequence of activation (Rosenbaum et al., 1945).

The conduction times from pre-excited site to RVA endocardium in these two patients with WPW type A (I IO-I $20 \mathrm{msec}$, respectively) were longer than those recorded in two other cases of WPW type B (40-50 msec, respectively) (Castellanos et al., I972b). However, these findings do not imply that different values might not be recorded in other persons with this syndrome, depending on the variable location of the accessory pathways.

\section{Importance of catheter recordings}

Pick and Fisch (1958) emphasized that the diagnosis of WPW type A associated with intermittent right bundle-branch block was not difficult because the pre-excitation occurred in the chamber with the intact bundle-branch block, therefore allowing for the delta wave to coexist with the late QRS changes produced by right bundle-branch block. Unfortunately similar electrocardiographic changes are seen in beats with pure WPW type A when the right ventricle is activated after the left, not because the right branch is blocked but as a consequence of the specific modality of intraventricular conduction characteristic of an impulse propagating from the posterior part of the ventricles in an anterior direction.

This communication stresses the importance of intracardiac electrograms in establishing the correct diagnosis. Moreover, a recent report from our department (Castellanos et al., 1972b) indicated how their value was enhanced by simultaneously recorded vectorcardiograms.

In beats with pure 'complete' right bundlebranch block a preterminal-terminal rightwards oriented delay was associated with normal, or prolonged PR (or StV), HV, and RVA intervals. Coexisting initial and rightwards oriented terminal delays were seen in beats with WPW type A coexisting with 'complete' right bundle-branch block as well as in those with pure WPW type A. Whereas in the former instances the initial delay was due to pre-excitation and the terminal conduction abnormalities to right bundle-branch block in pure WPW type $\mathbf{A}$ (resulting from exclusive conduction through the accessory pathway), both types of delay were due exclusively to the bizarre activation pattern seen in beats propagating from an ectopic ventricular site, regardless of whether they reached this area (from the atria) through an accessory pathway, or whether they originated there (spontaneous or induced extrasystoles).

\section{Duration of StV interval}

During high atrial pacing pre-excitation occurred even when the StV intervals were within normal limits (greater than $120 \mathrm{msec}$ ), probably because this interval included conduction time through the accessory pathway as well as through the atria, from the paced site to its upper entrance, which presumably was located somewhere in the left atrium.

\section{References}

Castellanos, A., Jr., Agha, A. S., Befeler, B., and Castillo, C. A. (1972a). A study of arrival of excitation at selected ventricular sites during human bundle branch block using bipolar catheter electrodes. Chest. In the press.

Castellanos, A., Jr., Agha, A. S., Portillo, B., and Myerburg, R. J. (I972b). Usefulness of vectorcardiography combined with His bundle recordings and cardiac pacing in evaluation of the pre-excitation (Wolff-Parkinson-White) syndrome. American fournal of Cardiology. 30, 623 .

Castellanos, A., Jr., and Castillo, C. A. (1972). His bundle recordings in right bundle-branch block coexisting with iatrogenic right ventricular pre-excitation. British Heart fournal, 34, 153.

Castellanos, A., Jr., Castillo, C. A., and Myerburg, R. J. (197I). Bipolar coronary sinus lead for left atrial and left ventricular recording. American Heart fournal, 81, 832.

Castillo, C. A., and Castellanos, A., Jr. (1970). His bundle recordings in patients with reciprocating tachycardias and Wolff-Parkinson-White syndrome. Circulation, 42, 271.

Durrer, A., Schoo, L., Schuilenburg, R. M., and Wellens, H. J. J. (1967). The role of premature beats in the initiation and termination of supraventricular tachycardia in WolffParkinson-White syndrome. Circulation, 36, 644.

Laham, J. (1969). Le Syndrome de Wolff-Parkinson-White, pp. 159-168. Maloine, Paris.

Pick, A., and Fisch, C. (1958). Ventricular pre-excitation (WPW) in the presence of bundle branch block. American Heart fournal, 55, 504 .

Robertson, P. G. C., Emslie-Smith, D., Lowe, K. G., and Watson, H. (1963). The association of type B ventricular pre-excitation and right bundle branch block. British Heart fournal, 25, 755.

Rosenbaum, F. F., Hecht, H. H., Wilson, F. N., and Johnston, F. D. (1945). The potential variations of the thorax and the esophagus in anomalous atrioventricular excitation (Wolff-Parkinson-White syndrome). American Heart fournal, 29, $28 \mathrm{I}$.

Schamroth, L. (1971). The Disorders of Cardiac Rhythm, p. 247. Blackwell Scientific Publications, Oxford.

Requests for reprints to Dr. A. Castellanos, Jr., University of Miami School of Medicine, P.O. Box 875, Biscayne Annex, Miami, Florida 33152, U.S.A. 